\title{
On the Quest to Bestow Autonomy have We Conferred Poor Prognosis?
}

\author{
Mahesh Gowda ${ }^{1}$, Khushboo Dewani ${ }^{2}$ \\ Keywords: Covert medication, Prognosis, Proxy consultation, Treatment adherence. \\ Indian Journal of Private Psychiatry (2021): 10.5005/jp-journals-10067-0099
}

The Mental Healthcare Act (MHCA), 2017 has shifted the focus to a rights-based approach to provide treatment, care, and protection of a person with mental illness (PMI). ${ }^{1}$ The importance of clinicians and what they practice was stressed to promote dignity in clinical practice. The Mysore declaration has recognized the potential friction between the rights of patients who refuse medication, treatment and the benefits of involuntary treatment, as well as the role of the family members in the treatment of mental illness in India. ${ }^{2}$ There have been multiple hurdles in providing care for $\mathrm{PMI}$, the most common being the lack of insight into the patient leading to treatment default and poor compliance. Nonadherence to treatment is one of the psychiatry's greatest challenges. With PMI being acutely symptomatic, having cognitive impairments, poor judgments, treatment refusals, and persistent illness peruse. Being educated, internet friendly, "Google doctors," patients have been refusing treatments, coming in the way of treatment decisions sometimes leading to relapses and disruptive behaviors. Proxy consultations had become customary in the past more so in psychiatry to overcome this hurdle. Over the years, treating professionals have seen the family and friends of many patients, who are helpless and need assistance in either bringing the patient to the hospital or making them take treatment. Most of the proxy consultations were done by the family of a patient who is disruptive or unwilling for treatment and thus end up in covert medications as reported in literature. Covert medication in food is a relatively common practice. ${ }^{3}$ The right for treatment and the type of treatment was a collective decision taken by the family, the doctors, and the patient earlier, now the shift has been to a patientoriented approach, where the patient has a right to deny treatment, becoming an important hurdle in treatment planning. The rightsbased MHCA, 2017 makes it difficult for the prevailing practices of treatment by the family/caregiver and proxy consultations on behalf of the patients. However, MHCA, 2017 has been silent on the role of covert medications. This prevents the family from taking help and doctors from providing proxy consultations and covert medications during psychiatry emergencies. ${ }^{4}$ According to the recently conducted National Mental Health Survey (NMHS), the treatment gap of any mental disorder in India was reported to be as high as $83 \% .{ }^{5}$ Giving this autonomy and consequently, treatment refusals may further widen this treatment gap. Penrose's Law states that as the number of psychiatric inpatients declines, the number of prisoners increases. The relationship between the sizes of the mental health population and the prison population, outlined in Penrose's Law, needs to be revisited after MHCA, 2017, so are we making more offenders with treatment refusals? ${ }^{6}$
'Spandana Nursing Home (Post Graduate Institute, DNB Psychiatry), Bengaluru, Karnataka, India

${ }^{2}$ Department of Psychiatry, S Nijjlingappa Medical College and HSK Hospital, Bengaluru, Karnataka, India

Corresponding Author: Mahesh Gowda, Spandana Nursing Home (Post Graduate Institute, DNB Psychiatry), Bengaluru, Karnataka, India, Phone: +91 9035560000, e-mail: maheshrgowda@yahoo.com

How to cite this article: Gowda M, Dewani K. On the Quest to Bestow Autonomy have We Conferred Poor Prognosis? Ind J Priv Psychiatry 2021;15(2):55-56.

Source of support: Nil

Conflict of interest: None

Mental healthcare Act, 2017 allows consultation by a nominated representative of a patient or through an advanced directive. Without these, there is no place for proxy consultation. Covert medication is surprisingly a common practice in psychiatry healthcare, yet at the same time is highly underreported. ${ }^{7}$ As little as $40 \%$ of covert medication administration is actually documented in a patient's chart after it is administered. ${ }^{8}$ This decision to give medications covertly takes place amid several critical issues that include the consent process, pharmacological concerns to name a few. Here, the responsibility lies with the caregiver as well as the treating doctor. The ethical and legal issues associated with it have often led the doctors to shy away from giving medications covertly and thus be a target of family's anger. Also, if given, and any misadventure happens, it is the treating doctor who is questioned and liable for action. So always covert medication has been a double-edged sword, with the new MHCA guidelines and Telepsychiatry operational guidelines, the patient care on legal framework is at forefront. According to the current practice guidelines, patient's rights are honored and covert medications cannot be given.

As per the Telemedicine practice guidelines-2020, ${ }^{9}$ telepsychiatry consultation can be started by a family member. The family member could be a nominated representative, or family member or any person authorized by the patient to represent the patient. All telepsychiatry consultations initiated by a family member or nominated representative or a caregiver will be accompanied by explicit consent from the patient. A family member initiating a telepsychiatry consultation without a patient can be considered only in follow-up telepsychiatry consult, no first consultation can be done without the patient. However, there is no scope to consider the rights of the family for providing and seeking treatment for these patients.

(c) The Author(s). 2021 Open Access This article is distributed under the terms of the Creative Commons Attribution 4.0 International License (https://creativecommons. org/licenses/by-nc/4.0/), which permits unrestricted use, distribution, and non-commercial reproduction in any medium, provided you give appropriate credit to the original author(s) and the source, provide a link to the Creative Commons license, and indicate if changes were made. The Creative Commons Public Domain Dedication waiver (http://creativecommons.org/publicdomain/zero/1.0/) applies to the data made available in this article, unless otherwise stated. 
It also risks the constant delivery system of medications, thereby leading to relapses and reoccurrence of symptoms. Predictors of good prognosis of psychiatric illness outcomes have been studied, good social support, treatment adherence, insight into the illness, and good socio-occupational functioning are a few factors that prevent relapses and ensure recovery. ${ }^{10}$ Treatment nonadherence has been a significant factor in relapse. ${ }^{11}$ So, are we risking a relapse because of the rights of the patient? Giving autonomy to a patient with no insight into the illness prevents treatment adherence and thus increases the risk of relapse and poor prognosis. So is bestowing autonomy, a hindrance to good prognosis?

What are the rights of patients? Is it permissible to include consent for covert medications in the advance directive? What is ethical issue related to covert medication in food? The relapse of patients at the cost of their rights, is it justifiable? Is being rights oriented translating into poor prognosis? Do we redefine prognostic factors? We as treating psychiatrist understand the Hippocrates Oath of doing no harm, but is the family out of its purview? Is the right of patient the only important factor or can we think about a "collective right," right of the patient, and the family members?

Setting up Mental health Review Boards (MHRB), under MHCA, would help in overcoming this hurdle of treatment refusal in managing chronic psychiatric illnesses. MHRB's scope of ensuring treatment compliance through treatment orders may help in avoiding relapses and continuous illness.

\section{References}

1. Raveesh BN, Gowda GS, Gowda M. How right is right-based mental health law? Indian J Psychiatry 2019;61(Suppl. 4):S640-S644. DOI: 10.4103/psychiatry.IndianJPsychiatry_115_19.
2. Lepping $P$, Raveesh BN. The Mysore declaration. Int Psychiatry 2013;10(4):98-99. DOI: 10.1192/S1749367600004082.

3. Guidry-Grimes L, Dean M, Victor EK. Covert administration of medication in food: a worthwhile moral gamble? J Med Ethics 2020. DOI: 10.1136/medethics-2019-105763.

4. Gowda GS, Enara A, Raveesh BN, et al. Is it the right time to implement Community Treatment Order in India? Indian J Psychiatry 2019;61(Suppl. 4):S816-S820. DOI: 10.4103/psychiatry. IndianJPsychiatry_88_19.

5. Gururaj G, Varghese M, Benegal V, et al. National Mental Health Survey of India, 2015-16: prevalence, patterns and outcomes. Bengaluru: National Institute of Mental Health and Neuro Sciences; 2016. NIMHANS Publication No. 129; pp. 90-121.

6. Kalapos MP. Penrose's law: methodological challenges and call for data. Int J Law Psychiatry 2016;49(Pt A):1-9. DOI: 10.1016/j. ijlp.2016.04.006.

7. Abdool R. Covert medication: legal, professional, and ethical considerations. J Law Med Ethics 2017;45(2):168-169. DOI: 10.1177/1073110517720645.

8. Foy E, MacCara ME. Concealment of drugs in food and beverages in nursing homes: cross sectional study. Int J Pharm Compd 2005;9(4):256. DOI: $10.1136 / \mathrm{bmj} .38268 .579097 .55$.

9. Math SB, Manjunatha N, Kumar CN. Telepsychiatry operational guidelines-2020. 1st ed. Bengaluru: NIMHANS; 2020. Accessed on December 18, 2021.

10. Bodén R. Prognostic factors in first-episode schizophrenia: five-year outcome of symptoms, function and obesity [Doctoral dissertation, Acta Universitatis Upsaliensis]. 2010. Accessed on December 18, 2021.

11. Alvarez-Jimenez M, Priede A, Hetrick SE, et al. Risk factors for relapse following treatment for first episode psychosis: a systematic review and meta-analysis of longitudinal studies. Schizophr Res 2012;139(1-3):116-128. DOI: 10.1016/j.schres.2012.05.007. 